This is an Accepted Manuscript of an article published by Taylor \& Francis Group in Pastoral Care in Education 17/01/2020, available online:

http://www.tandfonline.com/10.1080/02643944.2020.1713871

RPED-2019-0026

\title{
Losing Oneself: Tutorial Innovations as potential drivers of extrinsic motivation and poor wellbeing in university students.
}

Dr. Mark Tymms \& Dr. John Peters

Keywords: Tutors, PDP, Self-Determination Theory, autonomy, intrinsic motivation, wellbeing ABSTRACT

The aim of this study was to examine the impact of an educational innovation, here Personal Development Planning (PDP), on student attitudes to learning when located within tutorial processes across a range of departmental and institutional settings at a single UK university. Departments were purposively chosen in accordance with Clegg \& Bradley's (2006) conceptualizations of PDP as relating to the type of development being sought from their students, here framed as employment, academic or professional. Drawing on a Sartrean Existential ontology and Self-Determination Theory, interviews with staff and students were analysed using Giorgio's (1975) existential phenomenological method in order to explore the relationship between PDP, the tutor process and their impact on the intrinsic motivation of students. The study found that the presence of PDP within the tutor systems explored commonly alienated students from the tutor/tutee process. External or structural requirements too often replaced student need and with that the relevance of the tutor process was diminished. The study also found that the projection of lecturer identities and expectations were reinforced through the introduction of PDP to tutor support systems, and that due to perceived incongruences between individual students and the characteristics held by those lecturers as academic and professional exemplars the perceived significance of tutoring was still further reduced. The conclusion was reached that the application of external outcomes to the tutor process reduced student autonomy, competence and relatedness and subsequently produced anxiety in many students through a perceived inability to act in accordance with those external demands. 


\section{Introduction}

Today the role of tutorial support remains a fundamental aspect of the Higher Education environment (Riddell \& Bates 2010), and yet there can be little doubt that the expectations attached to those systems of support are increasingly dynamic and uncertain as universities seek to cater for an ever-increasing range of students and socio-political responsibilities (Jabbar \& Mirza 2017). This is in part due to the fluid nature of socio-political expectations placed on Higher Education and the manner in which that fluidity is reflected within the attitudes and expectations of both individual institutions and practitioners. Where Small (2013) has defined tutor processes as inherently multifacetted, holistic, safe and student-centred, Furlong (2013) suggests that this position may no longer be tenable, arguing that the increasing perception of university education as passive to social and economic need has recontextualised lecturing as teaching which is inherently both more political and passive. The consequence, as Whittey (2014) explains, has been a push to express university education in terms of pragmatic standards, processes and outcomes that have inevitably focused practice on issues that are instrumental, universal and generalisable. As part of the university environment such concerns can be applied to changes within tutor systems and the potential promotion of communication patterns that may inevitably ignore the subjective dimensions of students' life and the intrinsic needs and goals that students carry beyond academic content alone.

If true, such a shift towards passive instrumentality will place far greater significance on the studenttutor relationship as a driver for professional and workforce modelling (Small 2013), and yet as Heganauer \& Volet (2014) argue whilst the tutor process may therefore be given a more significant role within university education it still remains largely under-researched and misunderstood. For instance, psychological needs typically associated with the tutor-student relationship, such as that of 'belonging', have always been seen as particularly impactful on student wellbeing and performance and especially where students are relocating to University from home (Bergin \& Bergin 2009, Bernstein-Yamashiro and Noam 2013). Perceptions of isolation have been associated with low selfesteem (Koivusilta \& Junttila 2015), low self-efficacy (Iskender 2009) and reduced attainment (Lee 2013). For Ross et al. (2014) the need to 'belong' has to be seen therefore as an essential human motivator and treated as such within the tutor role, but 'to belong' may be seen as a reciprocal process between the institution as a fixed and formal body with particular expectations regarding student identities and outcomes and the students themselves as a complex and dynamic group with experientially and existentially different routes towards entry into the same formal context. As such, where Wootten (2006: 118) frames the tutor process as a 'conduit between the student and the 
institution' the increasingly passive nature of the sector to its environment may inevitably instead focus on the relationship between students and their future socio-economic states post-study. Subsequently, where the character of those student groups becomes ever-more diverse through widening participation, and the demands placed on the tutor also become more sophisticated, nuanced and responsive (Jacklin \& LeRiche 2009), the role of the tutor may become increasingly problematic as greater inter-personal complexity is targeted towards an increasingly limited range of student attitudes and identities as educational outcomes.

As previously mentioned, such an increased focus on the tutor as a manager of individual complexity has often been shaped by changes in the socio-political environment in which university's exist. Today, we find education framed within an increasingly de-politicized capitalist framework, most commonly named neo-liberal (Davis \& Bansel 2007), in which diversity and widening participation are discussed in terms of individual empowerment and yet framed in a form of standardization and accountability which strives to commodify knowledge, control subjectivity, simplify and constrain the possibilities and visions of students and staff and the range of influences that they bring to the education process (Slater \& Giggs 2015). As such:

'Neo-liberal schooling is at its core an ontological struggle over subjectivity - our understandings of ourselves, our relationships to others, and the social, political and ecological contexts into which we are cast' (Slater \& Giggs 2015: 439).

Here the promotion of a hegemonic sense of identity, or the attempt to create and maintain a common student attitude to post-study life, has offered some authors a perceived resolution to such a struggle through the proposed unification of socio-economic and personal wellbeing and the projection of socio-economic responsibility onto the individual (Tymms et al. 2013, Clegg 2010, Bush \& Bissell 2008). In essence, socio-economic growth and individual will and well-being are merged into a single concept which is then open to standardization and accountability; development becoming something that then becomes universal and measurable (Wright 2011). In essence, socioeconomic wellbeing and individual wellbeing are treated as one and the same concern. As Hughes, et al. (2018) suggest, academics are completely aware of such tensions but are disempowered through a perceived inability to manage such a fundamental contradiction in their structural and interpersonal roles, expressions of disagreement being lost within the de-politicization of university education (Thorne \& Kouzmin 2006). 
Socio-economically, Bouchard et al. (2013) have viewed this discussion through the concepts of autonomy and choice. They argue that how you view the proposed benefits of autonomy and hegemony depend on the outcomes that you are seeking. Where providers are central to the discussion choice and autonomy, here seen as essentially similar, can be seen as drivers of enhanced provision in terms of quality and efficiency. Choice and autonomy are seen as socially shaped and 'externalized' and it is this model that has dominated social policy, social acceptance of external preferences being promoted as a perception of internal choice (Tymms et al. 2013). Alternatively, where the terms are targeted at the individual then student autonomy and the need for individual students to sit at the heart of their learning is maximized and motivations to choose become intrinsic, and thus more effective in terms of wellbeing and social empowerment. Here, autonomy becomes an internal state and not an external expectation of preference (Clarke, Newman \& Westerland 2007), a lens that relates to freedom and a lack of external interference; "the ability to pursue your own conception of the good life" (Bouchard et al. 2013: 2). Self-determinism can be seen as a necessary part of this model, contextual pressures acting to constrain choice within desired parameters and thus negate the opportunity to self-determine.

The significance for the tutor, and their efforts to account for the socio-political preferences on which their working environments are built, here hegemonic neo-liberalism, is that often sociopolitical preference may actively hinder the tutors' professional actions with regard to student support. As c suggest, the developmental directions of individual students cannot be viewed as entirely automatic but as intrinsically linked to their experienced social contexts and the ways in which social contexts act to support or restrict the freedom of the student to choose their own path forward. As such, the potential exists for tutees to subsequently be disadvantaged within an educational system that is no longer congruent with the learners immediate and long-term needs.

"Human beings can be proactive and engaged or, alternatively, passive and alienated, largely as a function of the social conditions in which they develop and function... our education systems, including tutoring, as a significant factor within students social environment, can drive student introjection of non-optimum psychological behaviours through the promotion of apathy, passivity, alienation and the rejection of personal responsibility" (Deci \& Ryan 2000: 67)

The inclusion here of terms such as passivity, alienation and responsibility can be directly linked to Deci \& Ryan's work on Self-Determination Theory and their associated rejection of contextual heteronomy and the externalization of goals and motivations (Deci \& Ryan 2012). Building a model 
of wellbeing as a dimension of intrinsic motivation, Ryan \& Deci contend that individual wellness is essentially reliant on a harmony and congruence between individuals and the contexts of which they are a part (Rijavec et al. 2006). Here, wellness, and as a consequence efficacy, become aligned with the freedom of individuals to work autonomously and competently within a context that has meaning for them, known as relatedness (Ryan \& Deci 2006). When these three things, autonomy, competence and relatedness are in place for the student so their work becomes intrinsically motivated (Tabernero \& Hernandez 2011), and it is this intrinsic motivation, which has been linked to wellbeing as well as other significant concepts such as persistence, creativity (Vallerand, Pelletier \& Koestner 2008), vitality (Ryan et al. 2009), and improved self-esteem (Deci \& Ryan 2012), factors that further drive the development of personal wellbeing and efficacy (Ryan 2009). As such, whilst the experience of autonomy, competence and relatedness, would appear to drive the acquisition of intrinsic motivation, so intrinsic motivation itself also further acts to support future experiences of those same dimensions.

Intrinsic motivations, and the expression of curiosity towards areas of significant internal interest, would therefore appear central to the perceptions of autonomy and control. These are the areas in which we best experience and express autonomy, competence and relatedness, and as such seek to unify different aspects of 'self'. They also maximise self-regulatory practices and provide conceptual and pragmatic links between intrinsic motivation, as central to Self-Determination Theory, and socio-cognitive concepts such as locus of control (Darner, R. 2012), self-efficacy (Sweet et al. 2012), learner malleability (Yeager \& Dweck 2012) and self-regulation (Schunk \& Zimmerman 2007), which have also been effectively linked to the issues academic performance and psychological wellbeing through the promotion of positive personal attributions (Jeng \& Shih 2008). According to research on the Locus of Control concept, to perceive oneself as in charge of oneself is a key requirement of both positive wellbeing (Bajwa et al. 2016) and performance (Ahmed 2018, Shepherd et al. 2006, Tella, Tella \& Adeniyi. 2011). Malleability, as described by Dweck, and the embedded need to perceive the 'self' as both central to the learning process has been consistently linked to higher academic performance across a wide range of socio-cultural and economic contexts (Costa \& Faria 2018, Claro, S., Paunesku, D., \& Dweck, C. S. 2016), whilst efficacy and self-regulation have been found to drive personal performance through a similar focus on autonomy, competence and relatedness as central to Self-Determination Theory (Tella, Tella \& Adeniyi 2011). Within all of these perspectives lies the same recognition of 'self-as-behavioural-driver', and the ability of the individual to perceive themselves as both in charge of their own future and capable of achieving that desired future state when facing an ever-fluid individual and social context (Cupani et al 2010). 
Autonomy can therefore be conceptualized as essential to the development of intrinsic motivation and the rewards that stem from that position. Whilst, Bandura (1989) has dismissed the concepts of autonomy and heteronomy as pseudo issues within self-efficacy Ryan argues that autonomy is strongly involved in decisions surrounding the contexts of choice beyond simple evidenced ability. Here issues of locus remain part of efficacy but are not reduced to it and as such guide the regulation process through the establishing of autonomy, competence and relatedness.

Promoting autonomy, together with the need for competence and relatedness, may therefore be seen as the provision of an essential nutrient required for personal engagement and growth. Poor early provision of such concerns may lead to less intrinsic motivation, and lower levels of emotional self-regulation, resilience and internal/external unity in areas where support has not been sufficient. Education has been shown to be one such area in which an individuals' experiences of support significantly impacts on their later educational decisions, attitudes and behaviours (Guay et al. 2003). Indeed, work on adaptive tutoring by Osrow \& Hefferman (2015) has shown clear links between student choice as an intrinsically motivated dimension of personal tutor systems and academic performance, whilst Alves (2019) has evidenced a similar link between student-centred pastoral care and the wellbeing of BAME students in the UK.

Key to this process is the depth at which external social demands are internalized by the individual. This depth can control the ways in which the individual perceives themselves as autonomous. Here the instrumentality of an act can still be perceived as personally positive as long as it seen as congruent with their personal choices; as such they become issues of choice and not compliance. Here, autonomy acts on a continuum between choice and compliance. Where motivation remains internal, or intrinsic, so research suggests a positive link to wellbeing and academic performance; intrinsic motivation positively correlating with life-goal attainment and psychological well-being and extrinsic motivation instead with ill-being and poor life-goal attainment (Niemic et al. 2009).

Referencing Deci \& Ryan (2012) constraint occurs where the internalization of external demands and expectations dominates that process. We internalize roles and behaviours that are socially driven and originally alien to us. Behaviour as such can be attributed to others rather than self and autonomy is removed, which leads directly to an external locus of control where success is perceived as originating outside the individual. Here, heteronomy is strongest where compliance underpins action, which is known as 'external regulation' and which can lead to the alienation of the individual from the action being undertaken and thus prevents intrinsic motivation due to the externality of the demands being made of the individual. Here amotivation takes place where the individual fails to relate, or establish congruence, with the actions or outcomes being sought. 
This form of introjection is characterized by internal conflict where the autonomy of the individual is set against the demands of the surrounding context. The subsequent sense of helplessness diminishes engagement unless coerced in ways that raise relevance for the individual. Here, the potential struggle between economic and individual wellbeing and efficacy discussed previously, and as reflected within the associated issues of intrinsic and extrinsic motivation, gains educational relevance. It is also the point at which we can start to explore the ways in which educational innovations, here PDP, act to support or hinder the development of intrinsic motivation for the student and as such their efficacy, potential achievement and personal wellbeing.

\section{Method}

As discussed at length in Tymms (2018) the aim of this research was to understand the individual relationships of both staff and students at a single University to PDP, Personal Development Planning, where that innovation had been placed within the tutor process. Institutional and departmental documentation in association with staff interviews were analysed to explore the range of ways in which PDP as an educational innovation was being shaped by practitioners and their allegiances to their own educational models and the disciplines in which they taught. Departments were purposively chosen in accordance with Clegg \& Bradley's (2006) conceptualizations of PDP as relating to the type of development being sought from their students, here framed as employment, academic or professional. The use of categories was seen as dimensions of the increasing level of instrumentality within university education (Whittey 2014) and the adoption of an increasingly teacher-orientated framework in response to the political and economic stakeholders that effectively define the university environment (Furlong 2013). In addition, interviews with students further enlightened the discussion by creating links between the ways in which PDP was being presented by staff and the students' experiences of those efforts. In this way the exploration of PDP as an educational and tutorial innovation could be placed directly into the 'learning millieu' (Partlett \& Hamilton 1972: 14); the cultural, psychological and social networks within which teaching and learning inevitably take place.

To emphasize the potential impact of autonomy as dimension of lecturer and learner action a Sartrean existential-phenomenological lens was also adopted as an ontological frame. For Sartre, choice is a fundamental aspect of 'self' as an ontological concept; to be 'self' demands the freedom to be 'self' (Sartre 1956). Society and 'self' then exist as a paradox in which 'self' is both individual and social at the same time due to the fact that people always exist socially and are therefore always open to what Sartre called 'over-determinism' (Sartre 2007: 79) where context does not permit 
freedom but instead seeks to use its power to shape and constrain 'self' (Spinelli 1995). It is within this process of constraint that Sartre, as with Ryan and Deci, grounds the personal development of anxiety, defensiveness and ill-being (Sartre 1969, Spinelli 2008). It is also within this process that the essential and fundamental ideas underpinning the conceptualization of Ryan \& Deci have here been interpreted as a psychological form of a philosophical ontology, albeit a philosophical model that would essentially reject the psychological proposition that 'self' as experienced can be measured and generalized. In accordance with this dimension of Sartrean thought the initial student interviews and their analysis were presented as individual cameos which could then be brought back together as only indicative representations of experience, generalizations being seen as guilty of hiding the fundamental subjectivity of individual realities (McCune \& Entwistle 1999). This was a significant dimension of the work, Trowler (2011) commenting that the need of increased educational politicization to simplify and normalize the educational environment has acted to over-simplify our understanding of it and at the same time disempowered students as active participants in their own learning journeys. As Peters has argued in specific reference to the introduction of PDP:

"Higher Education (HE) policy on implementing PDP implied that students would be grateful recipients of whatever system an institution provided. Yet experienced practitioners [have] consistently reported a wide variety of responses, ranging from creative engagement, through compliance, to active resistance." $(2006, p .7)$

The specific focus of the research was therefore not to simplify the 'learning milieu' as an act of convenience (Lefcort 1981) but seek to reveal the inherent complexity of the lecturer-learner relationship. Naturally, the adoption of an existential ontology acted to reinforce difference above similarity, but a fundamental dimension of the work was to act as a counter-balance to Trolwers' recognition of contextual oversimplification. However, the adoption of an existential foundation was not simply a methodological choice but a philosophical one, Mairet (2007) clarifying Sartre's position that objective understanding can only be found through subjective experience where our perceptions of 'self' and 'other' are only ever experienced subjectively. This makes the research process more complicated in that it binds the researcher to the research and denies the use of 'bracketing' as favoured within Husserlean transcendental phenomenology. Data, in this model, can never be viewed neutrally but is always the product of an interpretive act (Zayed 2011), a level of interpretation that requires the researcher to remain open at all times to the reader (Cousins 2009) and driven to present conclusions that possess a clear underpinning rationale even if the reader disagrees with that viewpoint (Giorgio 1975). 
Originally, 5 discipline areas were chosen through their use of PDP as a tutorial tool. Participant confidentiality, an ethic made more significant by the adoption of an existential framework and the prioritization of the subjective individual that comes from that, was reinforced by the integration of each discipline into the three PDP types suggested by Clegg \& Bradley (2006). By framing each as a 'bounded system' (Mukherji \& Albon 2010) defined by a particular model of academic, employment or professional practice the contextual tone could be maintained without revealing the actual subject area being discussed by name. Furthermore, any named references to the topic areas being explored were also excluded from the transcription and citation processes.

Following an analysis of the forms of PDP being offered by each discipline a minimum of two lecturers were then interviewed as representatives of each area, and between two and four students from each. As contextual representatives, staff interviews were analysed in accordance with Braun \& Clarke's (2006) thematic phenomenological method, whilst student interviews were analysed using Giorgio's (1975) existential phenomenological method as a reflection of the proposed individuality of 'self' emphasized in the original Sartrean lens, although the final stage of the model was removed due to its aim to seek objective generalizations from subjective realities. For this article, however, both sets of data will be brought together through the aforementioned themes as discussed within Self-determination theory.

\section{Findings}

As already discussed educational attitudes towards autonomy have been significantly influenced by the changing dynamics of socio-political pressure and the subsequent atmospheres in which educational directions, processes and outcomes are shaped. Currently, efforts to politicize educational outcomes for economic justification have focused on forcing policy and practice towards each other (Trowler 2011, Slater \& Giggs 2015) as the needs of economic stakeholders have come to the fore of educational discussions entrenched in issues such as quality, accountability and employability (Salter \& Tapper 2000). In essence, the universities have been forced into a defensive position in which the future of the sector has become reliant on its ability to align itself with economic drivers beyond its own boundaries (Boud \& Falchikov 2006). PDP was founded within such tensions and indeed was offered as a neutral bridge between the two (Jackson 2001a) in the early literature offered to the sector by the Progress File Implementation Group, or PFIG, that had been initially formed to promote the promotion and acceptance of PDP.

Although absolute definitions of PDP, and the outcomes being sought through it, have always proved elusive (Clegg 2004, Fry et al. 2002), within that confusion can be found a core theme of 
student direction to what could be viewed as a socio-economic priority and with that a final form of student thought and action that would align them with socio-economic need at a lifelong and lifewide level (Jackson 2001b). As such PDP as presented by the PFIG may have been less about student performance and wellbeing and more the students' post-institutional behaviours. Those preferred outcomes can be linked to employability (Jackson \& Ward 2004, East 2005), identity management (Buckley 2008, James 2009), and self-regulation as recognition of an individual's responsibility to remain responsive to the changing needs of the marketplace (Jackson 2001b, Clegg \& Bradley 2006, Barnett 2003). In essence, whilst Jackson and the PFIG were viewing PDP as a potential bridge between educational and socio-economic needs, authors such as Clegg (2010) and Bush \& Bissel (2008) were seeing it more as a neoliberal tool for the unification of social and personal wellbeing in accordance with market forces. From this perspective PDP could be seen as far from being neutral but instead as a market-driven imperative from a single side of the aforementioned divide.

For this discussion the political nature of the innovation is highly significant in that, if true, at the core of the PDP innovation was a fundamental intention to deny student autonomy through the proposed imposition of a particular orientation towards the world. Individual wellbeing was being aligned to socio-economic wellbeing at a fundamental level and for authors such as Jackson (2007) and Edwards (2005) such an action was far too important to allow students choice in whether or not they would agree to it (Jackson 2007). As Boud \& Falchikov (2006) explained such an imperative was a fundamental dimension of the contemporary university environment:

"The raison d'être of a higher education is that it provides a foundation on which a lifetime of learning in work and other social settings can be built. Whatever else it achieves, it must equip students to learn beyond the academy once the infrastructure of teachers, courses and formal assessment is no longer available." (2006, p.399)

However, the university in question had found early efforts to introduce a generic form of PDP difficult to enforce and in line with Jackson's early comments about the innovations potential to be fluid across different contexts, responded by enforcing the innovations uptake at the university as a whole by allowing PDP to be shaped to the perceived needs of individual departments. How staff in this study responded to this position proved to be highly complicated and unpredictable, as was expected by Jackson and the PFIG who said that since the innovation had stemmed from practitioner research so that groups were ultimately responsible for the innovations introduction and the forms that were appropriate for each discipline context to which it was to be applied (Jackson et al. 2004). As such whilst the innovation was initially based on an externalized set of fundamental expectations how it was to applied in its' final forms was the responsibility of individual institutions and lecturers 
(Jackson et al. 2004). Such a move was shaped by an expectation of resistance by staff and the threats to their own autonomy as professionals and subsequently responsibilities for any loss of student autonomy could be aligned with that inter-staff resistance and not the external powers initiating it.

In this instance, it was a decision that effectively depoliticized the innovation and few lecturers explicitly mentioned such a political influence, that tension being relocated in discussions around the relationship between the implied core assumptions that PDP carried and their own attitudes to both themselves as lecturers and representatives of a particular academic or professional domain. Some interviewees, such as lecturer Richard, saw PDP as a direct attack on their roles as educator, arguing for the need to define education as more than a tool for employability. As Richard argued:

"I mean from a students' point of view if they're doing a degree to get a job I can understand it but in my mind education is not just about that and I have difficulty with that functional view of education as if it's simply about employability..."

However, for most, the major focus was on how the innovation could be applied to the tutor-tutee relationship in a way that supported the professional and academic identities of the students whilst also fulfilling the needs of the institution to have evidence of its application within all programmes of study across the university. However, an unforeseen consequence of this relocation was the ideas driving PDP were effectively relocated from the requirements of each programme to the attitudes of individual lecturers as exemplars of their own discipline. The university had made their decision on the assumption that a singular and coherent identity could be identified and attached to each educational context, but, in reality, this was not possible and lecturing staff too often responded by seeing PDP as a reflection of their own identities and not the generic departmental position that had had been laid down in the formal structures of their programmes. In addition, because many of the lecturers expressed confidence in themselves as an obvious exemplar of their area, and thus a clear role model to which the students would inevitably move, so the processes of introducing the innovation to the students proved largely limited in both the time given them and the levels of reinforcement that would take place through the courses.

For instance, in one professionally focused course one lecturer denied the need for reflective practitioners in the workplace. They felt that this position reflected their own experiences within their profession and had responded by ignoring reflective thinking in their own practice. Students being tutored by that member of staff would experience this in contact time with their lecturer and be directed away from reflection within their work. However, for another lecturer reflective practice 
was key to the professional identities which they were representing and therefore made it central to their PDP work as tutors. Both staff members were actively engaged with using PDP as a tutorial tool and both saw it as reflection of desirable professional practice, but in no way were the two lecturers offering a unified model. For the students, the consequence of this was that where the students being tutored felt that the ideas that were being given to them were congruent with their own then they engaged with their PDP, but when it didn't then they would withdraw. As James, a student working within an academic model of PDP stated:

“... if you do [PDP] for extra value but your personal tutor isn't actually interested and they don't ask to see it then you ask yourself why you've bothered doing that. What a waste of my time."

A significant aspect of this tension was that both lecturers still saw all cohort members as similar due their initial request to join the relevant profession. As Sandra, lecturer on a professionally orientated programme explained:

"To a certain extent I think that it's part of the nature of the students that we recruit that they all want to be a [practitioner] and with that comes a training programme which is tied to a set of standards that are national standards on which there is no negotiation so in a sense the type of students that come on our course almost know - part by prospectus, partly by open days, partly by induction, partly by the interview process - what they're coming in to."

In essence, although both members of staff projected a different view of their own profession they still expected to be in control of the tutor-tutee relationship because of the presence of specific professional frameworks and the perceived wish of the students as a coherent body to adopt those frameworks as fully congruent with themselves, which was not the case. In essence, autonomy was to be denied through the action of professional expectations (Pitt 2010) whilst incongruence and diminished efficacy, produced through that incongruence, were largely ignored due to the priorities of professional membership. In this form tutees were not to be tutored in accordance with their own individual needs at any one time but in how to align themselves with those aforementioned professional expectations even if this meant reducing the tutor time being offered to a tick-box exercise to ensure progression through the course. In essence, space and processes originally designed to promote self-reflection and critical self-awareness became a process of externalization.

As Felicity, programme leader of professionally orientated module, expressed:

"I know, I mean it's a very top-down model... you must stick to this model. Where's the negotiation? Where are the values and what's driving those standards? Ultimately, whose outcomes 
are they and whose agenda is it? And very often... it's someone else's agenda and it's an inappropriate set of outcomes."

As Pitt (2010) previously explained, there may exist an inevitability that student autonomy will be negatively impacted on when seeking membership into a profession, and that such a limitation will also be passed on to the tutor-tutee relationship. Indeed, it may also therefore be expected that professional membership is reliant on the student denying their own autonomy by creating individual-contextual congruence in order to ensure the acquisition of that membership. It is a point that Deci and Ryan (2012) discuss; their point being that where the context can be presented in such a way that it becomes willingly 'introjected' by the individual then the student still perceives themselves as autonomous. Where congruence cannot be identified or produced then it is likely that without the appropriate tutor support anxieties created through a perceived lack of congruence and competence will pressure those students to consider withdrawal.

For student Patricia, such an acknowledged incongruence between herself and the person being sought brought concerns over her long-term future in the profession.

"I personally [went] home feeling, not jaded but really depressed because I get so worried that four years down the line... I'm going to have to turn round and say 'oh... we just can't do it'."

Similarly, for Elizabeth, fellow student under lecturers Sandra and Felicity, issues surrounding such an unpredictable internal and external educational context brought with them severe emotional problems where that unpredictability was seen as creating a space in which personal congruence was deemed impossible and that they were subsequently forced into contextual passivity. Explaining lecturer unpredictability and the manner in which that made her reliant on each lecturer and placement supervisors as significant and yet highly idiosyncratic resources, Elizabeth explained:

"And that [inconsistency] really undermined my confidence in what I felt I could contribute to [my learning]... They were carrying me and I didn't like the fact that they were carrying me."

Sarah, student on the same course, offered a similar perspective of both the required academic and the PDP process, claiming that neither allowed for any real sense of ownership or expression. For Sarah, the ability to replicate professional and formalized standards as defined by those marking the work completely characterized the writing process. 
"In terms of the assignments you just have to give them what they want to pass... they said you just have to pass, and if you don't pass then we'll help you pass... It wasn't an option for us not to pass. Those people who didn't pass were simply told what to put in them to pass."

Regarding Self-Determination Theory, and the need for autonomy, it was interesting that for Sarah the freedom to fail was seen as an important part of their learning journey.

In terms of a potential conflict between discipline and individual identities and the perceived need to establish congruence with external models of identity, similar patterns were found with areas driven towards particular academic identities, as promoted within specific disciplines. As with the professional model already discussed the nature of academic identity was commonly perceived as unified but was ultimately fragmented according to the diverse perceptions of self within staff members. Here, however, the consequences for the student may be perceived as being greater than the professional context already discussed due to the inherently fluid nature of academic identity and the greater psychological variables that such a fluid state produces. For instance, within the same department one lecturer framed their academic identity through resistance to institutional pressures and ideologies. As Barbara, lecturer on an academically orientated programme, explained:

"I do wonder sometimes what goes on in these personal tutorials. Some people do it by the book and some people don't even open the book."

Due to the subsequent unwillingness to align their discipline with socio-economic models they refused to participate with the innovation process and the student experience of them was shaped within a very traditional and defensive model of academic tutoring. For another lecturer within the same department, they saw their discipline identity as highly specific and thus used PDP within the tutoring system to focus on the student acquisition of the specific characteristics required to make them academics, characteristics which included the denial of reflective practice. For that lecturer, the PDP process was specifically about pragmatic skills acquisition:

"Well our PDP skills are really practically based things, so they might be learning how to use certain types of apparatus so that when they go for jobs they already have those abilities there." Indeed, in this instance PDP as a process was really about student entrapment within the acquisition of those pragmatic objectives.

"We build it in so that they can't escape it... because you can always do all of these wonderful things through the personal tutorial system but they all fall by the wayside because the 
students don't come... they have to go to those tutorials and once you've got them in here then you can do the PDP because you've got them trapped."

Finally, a third lecturer in the same department openly grasped the external fundamental carried within PDP and willingly shaped their tutoring practices within the need to similarly shape the student towards those expectations.

"I think that it is very much something that encourages reflection on yourself personally... somehow you have to get over the idea that we are constantly learning and reflecting and gathering new experiences and information, and if like me you forget about them then it's also a way in which you can be a little bit more systematic in gathering that information and utilizing it well."

In each case the staff member in question had responded to PDP in line with their own positions and subsequently acted to move the focus of the tutor-tutee system away from the specific needs of the student and towards those shaped within those externalized demands represented by the relevant PDP process.

In this instance, for the academically orientated students, as with the professional context, their responses could be explained through their ability to either find congruence with the individual tutor frameworks to which they were being placed or accept that model as their own. However, again where that was not possible then tutor contact declined as relevance to themselves, and the perceived ability to fulfill the particular tutorial function being asked of them, created anxiety and withdrawal. In the instance above, PDP was mandatory but through that act contact with the tutor too often became resented. As academically orientated student Ann explained:

"You have to get those meetings just to pass the course and you think 'well I've got nothing to talk about'. You have to find someone just to sign the form to pass and so a lot of people find it really annoying."

Fellow student Rose, added to this by highlighting a perceived deterioration in the tutor-tutee relationship as the process became increasingly centred on PDP requirements; a change deemed as negative by staff and students alike.

"I've just had a couple of meetings... in fact I didn't even manage to get a second meeting and they just said not to worry and that they'd put me down as a pass. I mean I did try, but my tutor couldn't fit me in and I did try somebody else, and somebody else but they couldn't fit me in." 


\section{Discussion}

Before summing up these findings in terms of Self-Determination Theory it is worth briefly revisiting the model and the possible academic and psychological consequences of denying students a sense of autonomy, competence and relatedness within their work. Central to both the model and its consequences is the need to allow the individual to work intrinsically and towards goals that possess genuine meaning for each person. For Ryan, intrinsic motivations, and the expression of curiosity towards areas of significant internal interest, appear central to the perceptions of autonomy and control. These are the areas in which we best experience and express autonomy, competence and relatedness and as such seek to unify different aspects of self. They also maximise self-regulatory practices in order to best achieve unification, and drive the development of an internal locus of control. Without this freedom constraint can occur through the internalization of roles and behaviours that are socially driven and originally alien to us. Behaviour as such can be attributed to others rather than self and autonomy is removed leading directly to an external locus of control where success is perceived as originating outside the individual. As has already been stated the need for individuals to perceive themselves as autonomous has been correlated with improved selfesteem (Deci \& Ryan 1995) and wellbeing (Ryan, Deci \& Grolnick 1995). Furthermore, Flink, Boggiano \& Barrett (1990) have also shown that teachers that offer autonomous support to their students also foster higher intrinsic motivation and curiosity, together with a greater willingness to accept challenge. There is therefore an existing research body that would suggest that students function best both in terms of academic performance and psychological wellbeing where those students are left to make decisions for themselves towards goals and outcomes that fully reflect their individual worlds.

And yet, as Jackson suggests, PDP was often viewed as working beyond the student and towards the demands of the workplace and as such it was being demanded by a future abstract environment and not the students themselves. Student and socio-economic wellbeing were being treated as the same thing and thus a universal and necessary dimension of their post-university identities. Where this was deemed too important to be trusted to the student the question must be asked as to whether this perceived level of significance originally came from educational stakeholders or educators that deemed it appropriate to act on the behalf of their students.

Indeed, if we look at the findings a common theme was that of practitioners making assumptions and universalities of cohort characteristics, and equally viewing themselves as role models on which the future actions and beliefs of students should rest. In essence, even though practitioners promoting PDP to the sector and utilizing PDP within their tutee support practices talked about 
supporting students towards autonomy and self-regulation (Jackson \& Ward 2004), that goal was too often framed within external demands and expectations, be those professional, economic or egocentric. As such where the tutor process has been traditionally viewed as supporting students as they require it and in ways that they perceive themselves as needing support (Kitsantas \& Chow 2007) by adding PDP to that process those perceptions of difficulty and even inadequacy were rooted in the beliefs and expectations of others, be those either structural or interpersonal.

Of concern for tutor support as an on-going concern was the negative impact that this had on the students both academically and personally. For students that experienced those systems as incongruent with their own identity and beliefs, and deemed irrelevant to their academic or personal needs, withdrawal seemed far too often to be the consequence. Not only withdraw from the tutor-tutee process but courses of study where uncomfortable compliance was perceived as the only route of access to their envisioned future. As such, their route became framed specifically in a willing loss of autonomy, competence and relevance and through this, and accordance with both Deci \& Ryan and Sartre, the inevitable results of this were varying levels of expressed anxiety.

The introduction of generalized systems of learning aimed at specific local and general outcomes could perhaps therefore be seen as raising risks surrounding student performance and wellbeing, but by directing them through the tutorial system they also took away the space for students to raise concerns and seek support at a very personal level. In one instance, the evidencing of PDP participation became focused on getting slips signed by tutors during tutee space, but in this act the whole tutor-tutee process became bound to a particular administrative mechanism and tutor-tutee engagement suffered accordingly, tutorial relevance being lost. From all sides, in this instance, where PDP processes had been located almost solely within the tutor space so both PDP itself as an innovation and the role of the tutor had moved away from the basic and individual student support.

The issue for us here is that as Ryan \& Deci suggested the methods of introducing PDP to the tutor system discussed in this article, and the potential re-shaping of the tutor-tutee relationship that have accompanied those, may have acted for some students to promote negative attitudes towards both their academic potential and the worth of their identity through the loss of autonomy and the promotion of either the general or local context as primary point of focus for the educational environment.

A further concern was the identified tendency of staff members in both professionally and academically orientated course contexts to view their students as passive to their own expectations simply because of course entry. It was an issue that seemed to give the lecturers a perceived right to 
alter student perspectives without challenge and thus shape tutorial and PDP processes in their own image. This view seemed to be grounded on what proved to be a misguided perception of a universal context, and with it a universal set of attitudes and identities towards which students require direction. The consequence appeared a reflection of Sartre's concept of 'over-determinism' and a disregard for the individual student and their ability and willingness to accept pressure to comply. Yes, for some students, an existing congruence with staff perspectives supported this as an appropriate approach, but this was clearly not the case where that congruence was less clear. As has already be explained, Ryan \& Deci recognise that autonomy can be perceived where the individual adopts the external pressure as in line with their own but in this instance, however, the pre-existing presence of an assumed contextual identity clearly reduced the motivation to support the students that lacked that initial congruence and instead label those students as potentially unsuitable.

Finally, it should be noted that the PFIG's initial concerns regarding the acceptance of PDP by practitioners was not resolved by simply allowing different institutions and disciplines to shape the innovation in accordance with individual discipline contexts. This failure was rooted in a fundamental misunderstanding of the academic environment and the many views that can exist simultaneously with the same context. Whilst we have already spoken about the egocentric nature of the PDP provision as part of the tutor process, it should also be acknowledged that where PDP itself was rejected by individual staff members then so the fundamentals of the support mechanisms being provided to the students were damaged. At times, students moved to different tutors in order to limit incongruence, but more commonly the attitudes of the students to both PDP and the tutor mechanisms in place clearly suffered.

\section{Conclusion}

Much of the findings presented here should realistically have been expected, Rosenow (1973, p. 354) explaining that historically in formal educational practices "the student is first and foremost the object of the educational process, and never merely its subject". As such, as Peters (2006) has suggested a view of learners as passive has always been central to academic discussions at all levels. In essence, therefore, the denial of autonomy has always been a clear dimension of the university environment as the external drivers of pre-university education have been transferred increasingly to the university and post-university models of learning. However, as has already been argued in terms of well-being, Kasser \& Ryan (2006) and Deci \& Ryan (2012) have found that supporting intrinsic motivations and aspirations is positively associated with well-being indicators such as selfesteem, whilst also supportive in reducing anxiety and depression. Meanwhile, external aspirations 
were shown to be negatively associated with the same well-being indicators. As such the ways in which we educate and support our students may have serious potential impacts both for and beyond academic performance. The main difficulty highlighted in this research has been the potential for the use of innovations, such as PDP, to constrain the tutor process to mechanistic goals and diminish the tutors' ability to utilize the necessary fluidity and dynamism that has traditionally characterized such systems (Katz, Allbritton \& Connelly 2003). In essence, innovations such as that studied here may hinder the development and wellbeing students by diminishing the role of the students within their own learning and limit their ability to seek help when it is needed.

\section{References}

Ahmed, O. (2018) Locus of Control and Time and Study Management as Predictors of Academic Achievement. Bulgarian Journal of Science and Education, vol 12: 1

Alves, R. (2019) Could Personal Tutoring help improve the Attainment Gap of Black, Asian and Minority Ethnic Students? Blended Learning in Practice, Spring: 66-76

Bajwa, R. S., Batool, I., Azam, A., Ali, H. (2016) Impact of Locus of Control on Life Satisfaction among Distance Learning Students. Journal of Educational Research, vol. 19: 1

Bandura, A. (1989) Human Agency in Social Cognitive Theory. American Psychologist, vol. 44: 9, 1175-1184

Barnett, R. (2003) Beyond all reason: living with ideology in the university, Buckingham: Open University Press

Bergin C., \& Bergin D. (2009). Attachment in the classroom. Educational Psychology Review, 21, 141170. DOI: 10.1007/s10648-009-9104-0

Bernstein-Yamashiro, B., and Noam, G. G. (2013) Teacher-student relationships: A growing field of study. New Directions for Youth Development, 137, 15-27. DOI: 10.1002/yd.20045

Burchardt, T., Evans, M., Holder, H. (2013) Public Policy and Inequalities of Choice and Autonomy. Social Policy \& Administration, vol. 49: 1, 44 - 67 DOI: 10.1111/spol.12074

Boud, D. and Falchikov, N. (2006) 'Aligning assessment with long-term learning', Assessment \& Evaluation in Higher Education, vol. 31: 4. DOI: 10.1080/02602930600679050

Braun, V. and Clarke, V. (2006) 'Using Thematic Analysis in Psychology', Qualitative Research in Psychology, vol. 3. DOI: 10.1191/1478088706qp063oa

Buckley, C. (2008) PDP: From introduction to the present, The Higher Education Academy. Available at: www.learnhigher.ac.uk/Download-document/564-pdplitreview.htm 
Bush, H., \& Bissell, V. (2008) The evaluation of an approach to reflective learning in the undergraduate dental curriculum. European Journal of Dental Education, vol. 12: 2, 103 -110. DOI: 10.1111/j.1600-0579.2008.00508.x

Chirkov, V, Ryan, R, Kim, Y and Kaplan, U (2003) 'Differentiating autonomy from individualism and independence: A self-determination theory perspective on internalisation of cultural orientations and well-being', Journal of Personality and Social Psychology, 84 (1): 67-110.

Clarke, J., Newman, J. and Westmarland, L. (2007) 'The Antagonisms of Choice: New Labour and the reform of public services' Social Policy and Society, 7 (2): 245-253.

Claro, S., Paunesku, D., \& Dweck, C. S. (2016). Growth Mindset Tempers the Effects of Poverty on Academic Achievement. Proceedings of the National Academy of Sciences, 113, 8664-8668.

DOI: $10.1073 /$ pnas.1608207113

Clegg, S. (2004) 'Critical readings: progress files and the production of the autonomous learner', Teaching in Higher Education, vol. 9. DOI: 10.1080/1356251042000216615

Clegg, S. (2010) 'Time Future - the dominant discourse of higher education', Time \& Society, vol. 19: 3. DOI: $10.1177 / 0961463 \times 10381528$

Clegg, S. and Bradley, S. (2006) 'Models of Personal Development Planning: practice and processes', British Educational Research Journal, vol. 32: 1. DOI: 10.1080/01411920500402003

Costa, A., \& Faria, L. (2018) Implicit Theories of Intelligence and Academic Achievement: A MetaAnalytic Review. Frontiers in Psychology, vol. 9. DOI: 10.3389/fpsyg.2018.00829

Cousin, G. (2009), Researching Learning in Higher Education: An Introduction to Contemporary Methods and Approaches, Abingdon: Routledge

Cupani-Maria, M., Richaudde, C., Edgardo, M., Ricardo, R. P., \& Pautassi, M. (2010) An assessment of a social-cognitive model of academic performance in mathematics in Argentinean middle school students. Learning and Individual Differences, 20: 6, p659-663. DOI: 10.1016/j.lindif.2010.03.006

Darner, R. (2009) Self-Determination Theory as a Guide to Fostering Environmental Motivation. Journal of Environmental Education, 40(2): 39-49. DOI: 10.3200/JOEE.40.2.39-49

Davies, B., \& Bansel, P. (2007) Neoliberalism and education, International Journal of Qualitative Studies in Education, 20:3, 247-259. DOI: 10.1080/09518390701281751

Deci, E. L., \& Ryan, R. M. (1995) Human autonomy. In Kernis, M. H. (Ed) Efficacy, agency, and selfesteem. Boston: Springer. DOI: 10.1007/978-1-4899-1280-0

Deci, E. L., \& Ryan, R. M. (2000) The" what" and" why" of goal pursuits: Human needs and the selfdetermination of behavior. Psychological inquiry, 11: 4, 227-268. DOI:

10.1207/S15327965PLI1104_01

Deci, E. L., \& Ryan, R. M. (2012). Self-Determination Theory. In: Van Lange, P, A. M., Kruglanski, A. W., and Higgins, E. T (eds) Handbook of Theories of Social Psychology, Volume 1. London: Sage 
East, R. (2005) 'A progress report on progress files: The experience of one higher education institution', Active Learning in Higher Education, vol. 6. DOI: 10.1177/1469787405054240

Flink, C., Boggiano, A. K., and Barrett, M. (1990) Controlling Teaching Strategies: Undermining Children's Self-Determination and Performance, Journal of Personality and Social Psychology, vol. 59: 5, 916-924. DOI: 10.1037/0022-3514.59.5.916

Fry, H., Davenport, E. S., \& Woodman, T. and Pee, B. (2002) 'Developing Progress Files: a case Study', Teaching in Higher Education, vol. 7: 1. DOI: 10.1080/13562510120100418

Furlong, J. (2013) Education - An Anatomy of the Discipline. London: Routledge

Giorgi, A. (1975) 'An application of phenomenological method in psychology', in Giorgi, A. Fischer, C. and Murray, E. (Eds.), Duquesne studies in phenomenological psychology: Volume II, Pittsburgh, PA: Duquesne UP.

Guay, F., Senécal, C., Gauthier, L., \& Fernet, C. (2003). Predicting career indecision: A selfdetermination theory perspective. Journal of Counseling Psychology, 50(2), 165-177. DOI: 10.1037/0022-0167.50.2.165

Hagenauer, G., \& Volet, S. E. (2014). Teacher-student relationship at university: an important yet under-researched field. Oxford Review of Education, 40(3), 370-388. DOI:

10.1080/03054985.2014.921613

Hughes, G., Panjwani, M., Tulcidas, P., Byrom, N. (2018) Student Mental Health: The Role \& Experiences of Academics. Student Minds. Accessed from http://www.studentminds.org.uk/uploads/3/7/8/4/3784584/180129_student_mental_health_the _role_and_experience_of_academics_student_minds_pdf.pdf on 08.08.2018

Iskender, S. U. (2009) The Relationship between Self-compassion, Self-efficacy and Control Beliefs about Learning in Turkish University Students. Social Behaviour \& Personality vol. 37: 5, 711-720. DOI: $10.2224 / \mathrm{sbp} .2009 .37 .5 .711$

Jabbar, A., \& Mirza, M.(2017): Managing diversity: academic's perspective on culture and teaching, Race Ethnicity and Education, DOI:10.1080/13613324.2017.1395325

Jacklin, A., \& Le Riche, P. (2009) Reconceptualising student support: from 'support' to 'supportive', Studies in Higher Education, 34:7, 735-749. DOI:10.1080/03075070802666807

Jackson, N. (2001a), 'Personal development planning: what does it mean?'. The Higher Education Academy. Available at: http://www.heacademy.ac.uk/.../id465_pdp_what_ does_\%20it_\%20mean.pdf. Retrieved 12.11.2008

Jackson, N. (2001b) Understanding \& Expanding PDP: Helping Busy Academics, The Higher Education Academy, available at: http://www.heacademy.ac.uk/ id62_Helping_Busy_Academics_Report_of_the_Invitation_Seminar.pdf. Retrieved 12.11.2008

Jackson, N. (2007), 'Foreword', in Kumar, A. (2007) Personal, Academic \& Career Development in Higher Education: SOARing to Success. Routledge: Abingdon 
Jackson, N., Gough, D., Dunne, E. and Shaw, M. (2004), Developing an infrastructure to support an evidence-informed approach to Personal Development Planning, The Higher Education Academy

Jackson, N. and Ward, R. (2004) 'A fresh perspective on progress files: a way of representing complex learning and achievement in higher education', Assessment \& Evaluation in Higher Education, vol. 29: 4. DOI: $10.1080 / 02602930310001689028$

James, A. (2009) 'Personal \& Professional Development at University of the Arts London: Introducing PPD Coach', PDPUK, Issue 17. Available at: http://www.recordingachievement.org/news-andevents/publications/pdpuk.html

Jeng, Y-C., \& Shih, H-H. (2008) A Longitudinal Design Study on Self-Efficacy, Attribution, Goal Setting, and Mechanics Achievement in Department of Mechanical Engineering Students on Taiwan. The International Journal of Learning, 15: 11, 161-169

Kasser, T., \& Ryan, R. M. (1996). Further examining the American dream: Differential correlates of intrinsic and extrinsic goals. Personality and Social Psychology Bulletin, 22, 80-87. DOI: $10.1177 / 0146167296223006$

Katz, S., Allbritton, D., Connelly, J. (2003) Going Beyond the Problem Given: How Human Tutors Use Post-Solution Discussions to Support Transfer. International Journal of Artificial Intelligence in Education (IJAIED), 13, 79-116.

Kitsantas, A., \& Chow, A. (2007). College students? Perceived threat and preference for seeking help in traditional, distributed and distance learning environments. Computers and Education, 48(3), 383395. DOI: 10.1016/j.compedu.2005.01.008

Koivusilta, L., \& Juntilla, N. (2015) Psychosocial well-being, perceived loneliness and self-esteem among Finnish children. European Journal of Public Health, vol. 25: 3. DOI:

10.1093/eurpub/ckv175.131\#

Lee, J-S. (2014) The Relationship Between Student Engagement and Academic Performance: Is It a Myth or Reality? The Journal of Educational Research, 107:3, 177-185, DOI:

10.1080/00220671.2013.807491

Lefcourt, H. M. (Ed.) Research with the locus of control construct, vol. 1, New York: Academic Press.

Mairet, P. (2007) 'Introduction', in Sartre, J. P. (2007) Existentialism \& Humanism, London: Methuen \& Co

McCune, V. and Entwistle, N. (2000), The deep approach to learning: analytic abstraction and idiosyncratic development, Paper presented at the Innovations in Higher Education Conference, 30 August - 2 September 2000, Helsinki, Finland

Mukherji, P. and Albon, D. (2010) Research Methods in Early Childhood, London: Sage

Niemic, C. P., Ryan, R. M., Deci, E. L. (2009) The Path Taken: Consequences of Attaining Intrinsic and Extrinsic Aspirations in Post-College Life. Journal of Research in Personality; 73: 3: 291-306. DOI: 10.1016/j.jrp.2008.09.001 
Partlett, M. and Hamilton, D. (1972)' Evaluation as illumination: a new approach to the study of innovatory programmes', Centre for Research in the Educational Sciences, Edinburgh: University of Edinburgh

Peters, J. (2006) 'Researching student attitudes to Personal Development Planning', PDPUK, Issue 7. Available at: http://www.recordingachievement.org/news-and-events/publications/pdpuk.html

Pitt, A. (2010) 'On having one's Chance: Autonomy as Education's Limits', Educational Theory, vol. 60: 1. DOI: 10.1111/j.1741-5446.2009.00342.x

Riddell, S. \& Bates, N. (2010) The role of the personal tutor in a curricular approach to Personal Development Planning. Journal of Learning Development in Higher Education, November

Rijavec, M., Brdar, I., \& Miljkovic, D. (2006). Extrinsic vs. intrinsic life goals, psychological needs and life satisfaction. In Delle Fave, A. (Ed.), Dimensions of well-being. Research and intervention. Milan: Franco Angeli.

Rosenow, E. (1973) 'What is Free Education? The educational significance of Nietzsche's thought', Educational Theory, vol. 23: 4. DOI: 10.1111/j.1741-5446.1973.tb00617.x

Ross, J., Head, K., King, L., Perry, P. M., Smith, S. (2014) The personal development tutor role: An exploration of student and lecturer experiences and perceptions of that relationship. Nurse Education Today 34(9): 1207-1213. DOI: 10.1016/j.nedt.2014.01.001

Ryan, R. M. (2009) Self-Determination Theory and Wellbeing. WeD Research Review 1. Downloaded from https://richarddehoop.nl/upload/file/self-determination.pdf on 27.11.2019

Ryan, R. M., Deci, E. L., \& Grolnick, W. S. (1995). Autonomy, relatedness, and the self: Their relation to development and psychopathology. In D. Cicchetti \& D. J. Cohen (Eds.), Developmental psychopathology: Theory and methods (Vol 1, pp. 618-655). New York: Wiley.

Ryan, R. M., Deci, E. L. (2000). Self-Determination Theory and the Facilitation of Intrinsic Motivation, Social Development, and Well-Being. American Psychologist; 55: 1. DOI: 10.1037//0003066X.55.1.68

Ryan, R. M., and Deci, E. (2006) 'Self-regulation and the problem of human autonomy: Does psychology need choice, self-determination and will?' Journal of Personality, 74 (6): 1557-1586

Ryan, R. M., Williams, G. C., Patrick, H., and Deci, E. (2009) Self-Determination Theory and Physical Activity: The Dynamics of Motivation in Development and Wellness. Helenic Journal of Psychology, 6 : 107-124

Salter, B. and Tapper, T. (2000) 'The Politics of Governance in Higher Education: The Case of Quality Assurance', Political Studies, vol. 48

Sartre, J. P. (1956) Being and Nothingness, New York: Philosophical Library.

Sartre, J. P. (1969) Existential Psychoanalysis, Chicago: Henry Regnery Company

Sartre, J. P. (2007) Existentialism and Humanism, Brooklyn: Haskell House Publishers Ltd. 
Schunk, D. H. and Zimmerman, B. J. (2007) 'Influencing Children's Self-Efficacy and Self-Regulation of Reading and Writing through Modelling', Reading \& Writing Quarterly, vol. 23. DOI:

$10.1080 / 10573560600837578$

Shepherd, S., Owen, D., Fitch, T. J., \& Marshall. J. L. (2006) Locus of control and academic achievement in high school students. Psychol Rep. vol. 98: 2, 318-22. DOI: 10.2466/pr0.98.2.318-322

Slater, G. B., Bradford Griggs, C. (2015) Standardization and Subjection: An Autonomist Critique of Neoliberal School Reform. The Review of Education, Pedagogy, and Cultural Studies' 37. DOI: 10.1080/10714413.2015.1091259

Small, F. (2013) Enhancing the role of Personal Tutor in professional undergraduate education. Inspiring Academic Practice 1(1): 1-11

Spinelli, E. (1995) The Interpreted World: An Introduction to Phenomenological Psychology, London: Sage

Spinelli, E. (2008) 'Sartre and conflict: six lessons for coaching, Coaching: An International Journal of Theory', Research and Practice, vol. 1: 2

Sweet, S. N., Fortier, M. S., Strachan, S. M. Blanchard, C. M. (2012) Testing and Integrating SelfDetermination Theory and Self-Efficacy Theory in a Physical Activity Context. Canadian Psychology / Psychologie Canadienne, 53(4): 319-327. DOI: 10.1037/a0030280

Tabernero, C., \& Hernandez, B. (2011) Self-Efficacy and Intrinsic Motivation Guiding Environmental Behavior. Environment \& Behavior, vol. 43: 5, 658-675. DOI: 10.1177/0013916510379759

Tella, A., Tella, A., \& Adeniyi, S. O. (2011) Locus of Control, Interest in Schooling and Self-Efficacy as Predictors of Academic Achievement among Junior Secondary School Students in Osun State, Nigeria. New Horizons in Education, vol.59: 1

Thorne, K. and Kouzmin, A. (2006) 'Learning to Play the "Pea \& Thimble" Charade - The Invisible and Very Visible Hands in the Neo-Liberal Project: Towards a Manifesto for Reflexive Consciousness in Public Administration', Administrative Theory \& Praxis, vol. 28: 2

Trowler, P. (2011) in Saunders, M., Trowler, P. and Bamber, V. (eds) Reconceptualising Evaluation in Higher Education; the practice turn. Maidenhead: McGrawHill

Tymms, M. (2018). Implementing Educational Innovations: A Staff Perspective of Personal Development Planning. Research in Higher Education, vol 23: 4, 463-478. DOI:

10.1080/135967748.2018.1526904

Tymms, M., Peters, J. and Scott, I. (2013) 'Personal Development Planning: pedagogy and the politicization of the personal', Research in Post-Compulsory Education, vol. 18: 3. DOI: 10.1080/13596748.2013.819264

Vallerand, R. J., Pelletier, L. G., \& Koestner, R. (2008). Reflections on self-determination theory. Canadian Psychology/Psychologie canadienne, 49(3), 257-262. DOI: 10.1037/a0012804 
Whitty, G. (2014) 'Recent developments in teacher training and their consequences for the 'University Project' in education'. Oxford Review of Education, 40 (4).

http://dx.doi.org/10.1080/03054985.2014.933007

Wootton, S. (2006). Changing practice in tutorial provision within post-compulsory education. In Thomas, L. and Hixenbaugh, P. (eds) Personal Tutoring in Higher Education, Stoke on Trent: Trentham Books.

Wright, A. (2012) Fantasies of empowerment: mapping neoliberal discourse in the coalition government's schools policy, Journal of Education Policy, 27:3, 279-294. DOI:

10.1080/02680939.2011.607516

Yeager, D. S., and Dweck, C. S. (2012) Mindsets That Promote Resilience: When Students Believe That Personal Characteristics Can Be Developed. Educational Psychologist, 47(4): 302-314. DOI: 10.1080/00461520.2012.722805

Zayed, R. (2008) 'The Changing Nature of the Phenomenological Method: Lessons Learned from Dialogical Psychotherapy Research', Janus Head, 10: 2 
